\title{
Chondromodulin-1 in health, osteoarthritis, cancer, and heart disease
}

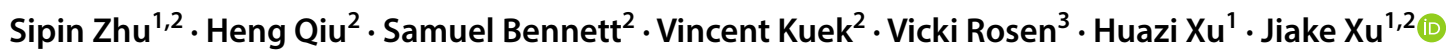

Received: 9 May 2019 / Revised: 3 July 2019 / Accepted: 9 July 2019 / Published online: 17 July 2019

(c) The Author(s) 2019

\begin{abstract}
The human chondromodulin-1 (Chm-1, Chm-I, CNMD, or Lect1) gene encodes a 334 amino acid type II transmembrane glycoprotein protein with characteristics of a furin cleavage site and a putative glycosylation site. Chm-1 is expressed most predominantly in healthy and developing avascular cartilage, and healthy cardiac valves. Chm-1 plays a vital role during endochondral ossification by the regulation of angiogenesis. The anti-angiogenic and chondrogenic properties of Chm- 1 are attributed to its role in tissue development, homeostasis, repair and regeneration, and disease prevention. Chm-1 promotes chondrocyte differentiation, and is regulated by versatile transcription factors, such as Sox 9, Sp3, YY1, p300, Pax1, and Nkx3.2. Decreased expression of Chm-1 is implicated in the onset and progression of osteoarthritis and infective endocarditis. Chm-1 appears to attenuate osteoarthritis progression by inhibiting catabolic activity, and to mediate anti-inflammatory effects. In this review, we present the molecular structure and expression profiling of Chm-1. In addition, we bring a summary to the potential role of Chm-1 in cartilage development and homeostasis, osteoarthritis onset and progression, and to the pathogenic role of Chm-1 in infective endocarditis and cancers. To date, knowledge of the Chm-1 receptor, cellular signalling, and the molecular mechanisms of Chm-1 is rudimentary. Advancing our understanding the role of Chm- 1 and its mechanisms of action will pave the way for the development of Chm-1 as a therapeutic target for the treatment of diseases, such as osteoarthritis, infective endocarditis, and cancer, and for potential tissue regenerative bioengineering applications.
\end{abstract}

Keywords Embryo $\cdot$ Heart $\cdot$ Fertility $\cdot$ Bone $\cdot$ Immune $\cdot$ Tumour

\section{Introduction}

The chondromodulin-1 (Chm-1, Chm-I, CNMD, or Lect1) gene was first cloned from foetal bovine cartilage as a $25 \mathrm{kDa}$ glycoprotein that could stimulate chondrocyte growth in the presence of basic fibroblast growth factor (FGF) [1]. Chm-1 has structural characteristics of a type II transmembrane glycoprotein with two cleaved portions: the $\mathrm{N}$-terminus contains a surfactant protein referred to as a chondrosurfactant protein, and the $\mathrm{C}$-terminus of the precursor protein

Jiake Xu

jiake.xu@uwa.edu.au

1 Department of Orthopaedics, The Second Affiliated Hospital and Yuying Children's Hospital of Wenzhou Medical University, Wenzhou 325000, Zhejiang, China

2 Molecular Laboratory and the Division of Regenerative Biology, School of Biomedical Sciences, M Block, QEII Medical Centre, The University of Western Australia (M504), 35 Stirling Hwy, Perth, WA 6009, Australia

3 Developmental Biology, Harvard School of Dental Medicine, Boston, MA 02115, USA consists of a $25 \mathrm{kDa}$ mature protein referred to as Chm-1, which is able to stimulate chondrocyte growth and to inhibit angiogenesis [1-4]. During endochondral bone formation, $\mathrm{Chm}-1$ is involved in the regulation of cartilage growth and vascular invasion prior to the transition of cartilage to bone [5-7]. The Chm-1 protein is mainly detected in the avascular region of pre-hypertrophic cartilage, and appears to prevent vascularization of cartilaginous anlagen during endochondral ossification $[8,9]$. Chm-1 may be also involved in the pathogenesis of conditions characterized by neo-vascularization, such as infective endocarditis, and cancers $[4,10]$. The aim of this article is to provide a current overview of the characterization of Chm-1, in terms of expression profiling, molecular structure, and biological function. Overall, Chm-1 appears to be involved in the regulation of tissue angiogenesis, cartilage development and homeostasis, and to be implicated in the onset and progression of diseases, such as osteoarthritis, infective endocarditis, and cancer. 
A

SP|O75829|CNMD_HUMAN MTENSDKVPIALVGPDDVEFCSPPAYATLTVKPSS-PARLLKVGAVVLISGAVLLLFGAI 59 SP|Q9Z1F6|CNMD MOUSE MTENSDKVPITMVGPEDVEFCSPPAYTTVTVKPSGSPTRLLKVGAVVLISGAVLLLFGAI 60 SP|P17404|CNMD_BOVIN MTENSDKVPIALVGPDDVEFCSPPAYAAVTVKPSS-PARLLKVGAVVLISGAVLLLLGAI 59 SP|070367/CNMD RAT MTENSDKVPITMVGPEDVEFCSPPAYATVTVKPSGSPTRLLKVGAVVLISGAVLLLFGAI 60 SP|O77770|CNMD_RABIT MTENSDKVPIALVGPDDVEFCGPPAYATVTVKPSG-PARLLKVGAVVLISGAVLLLFGAI 59

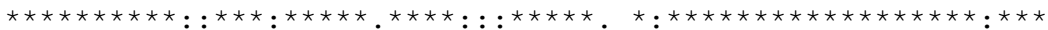

SP|O75829|CNMD HUMAN GAFYFWKGSDSHIYNVHYTMSINGKLQDGSMEIDAGNNLETFKMGSGAEEAIAVNDFQNG 119 SP|Q9Z1F6|CNMD_MOUSE GAFYFWKGNDNHIYNVHYSMSINGKLQDGSMEIDAVNNLETFKMGSGAEEAIEVNDFKNG 120 SP|P17404|CNMD BOVIN GAFYFWKGSDNHIYNVHYTMSINGKLQDGSMEIDAGNNLETFKMGSGAEEAVEVNDFQNG 119 SP|O70367|CNMD_RAT GAFYFWKGNDNHIYNVHYTMSINGRLQDASMEIDAANNLETFKMGSGAEEAIEVNDFQNG 120 SP|O77770|CNMD RABIT GAFYLWKGSDNHIYNVHYTMSINGKLQDGSMEIDARNNLETFKMGSGAEEAIEVNDFQNG 119

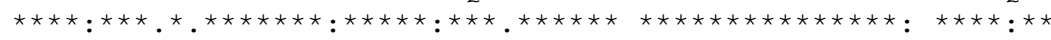

SP|O75829|CNMD HUMAN ITGIRFAGGEKCYIKAQVKARIPEVGAVTKQSISSKLEGKIMPVKYEENSLIWVAVDQPV 179 SP|Q9Z1F6|CNMD_MOUSE ITGIRFAGGEKCYIKAQVKARIPEVGTVTKQSI-SELEGKIMPANYEENSLIWVAVDQPV 179 SP|P17404|CNMD_BOVIN ITGIRFAGGEKCYIKAQVKARIPEVGTMTKQSISSELEGKIMPVKYEENSLIWVAGDQPV 179 SP|O70367|CNMD_RAT ITGIRFAGGEKCYIKAQVKARIPEVSTGTKQSI-SELEGKIMPVKYEENSLIWVAVDQPV 179 SP|O77770|CNMD_RABIT ITGIRFAGGEKCYIKAQVKARVPEVGTVTQQSISSELEGKIMPVKHEEEALVWVAVGQPV 179

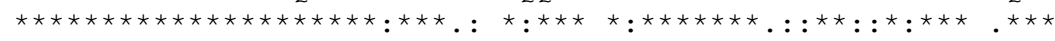

SP|O75829|CNMD_HUMAN KDNSFLSSKVLELCGDLPIFWLKPTYPKEIQRERREVVRKIVPTT-TKRPHSGPRSNPGA 238 SP|Q9Z1F6|CNMD MOUSE KDSSFLSSKILELCGDLPIFWLKPMYPKEIQRERREVVRNSAPST-TRRPHSEPRGNAGP 238 SP|P17404|CNMD_BOVIN KDNSFLSSKVLELCGDLPIFWLKPTYPKEIQRERRELVRKIVTTTTTRRLRSGPQGTPAP 239 SPI070367|CNMD RAT KDNSELSSKILEFCGDLPIFWLKPMYPKEI PRERREVVRSSAPST-TRRPHSEPRGNAGP 238 SP|O77770|CNMD_RABIT QDNSFLSARVLELCGDLPIFWLKPTYPKEIQRERREVVRKTVPTT-TKRPHSGPRGNPGP 238

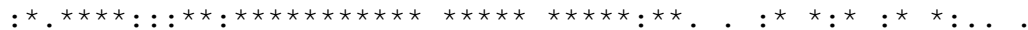

SP|O75829|CNMD HUMAN GRLNNETRPSVQEDSQAFNPDNPYHQQEGESMTFDPRLDHEGICCIECRRSYTHCQKICE 298 SP|Q9Z1F6|CNMD MOUSE GRLSNGTRPNVQDDAEPFNPDNPYHQQEGESMTFDPRLDHEGICCIECRRSYTHCQKICE 298 SP|P17404|CNMD BOVIN GRPNNGTRPSVQEDAEPFNPDNPYHQQEGESMTFDPRLDHEGICCIECRRSYTHCQKICE 299 SP|O70367|CNMD RAT GRLSNRTRPSVQDDEEPFNPDNPYHQQEGESMTFDPRLDHEGICCIECRRSYTHCQKICE 298 SP|O77770|CNMD_RABIT ARMRNDSRPSVQEDSEPFNPDNPYHQ-EGESMTFDPRLDHEGICCIECRRSYTHCQKICE 297

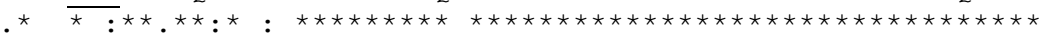

SP|O75829|CNMD HUMAN PLGGYYPWPYNYQGCRSACRVIMPCSWWVARILGMV 334 SP|Q9Z1F6|CNMD_MOUSE PLGGYYPWPYNYQGCRSACRVVMPCSWWVARILGMV 334 SP|P17404|CNMD-BOVIN PLGGYHPWPYNYQGCRSACRVIMPCSWWVARILGMV 335 SP|O70367|CNMD_RAT PLGGYYPWPYNYQGCRSACRVVMPCSWWVARILGMV 334 SP|O77770|CNMD RABIT PLGGYNPWPYNYQGCRSACRVVMPCSWWVARILGMV 333

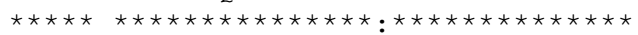

\section{B}

SP | 014960 | LECT2_HUMAN SP $|075829|$ CNMD

SP | 014960 | LECT2_HUMAN SP $\mid 075829$ |CNMD

SP 014960 | LECT2 HUMAN SP $\mid 075829$ |CNMD_HUMAN

GITGIRFAGGEKCYIKAQVKARIPEVGAVTKQSISSKLEGKIMPVKYEENSLIWVAVDQP 178
MTENSDKVPIALVGPDDVEFCSPPAYATLTVKPSSPARLLKVGAVVLISGAVLLLFGAIG 60
$::^{\star} \quad \star \star \star \star \star \star *$
SP | $014960 \mid$ LECT2_HUMAN SP|O75829|CNMD_HUMAN

$\mathrm{VKD}$

SP|O14960|LECT2_HUMAN GSTVYAP-----FTGMIVGQEKPYQNKN--AINNGVRISGRGFCVKMFYIKPIKYKGPIK 115 SP|O75829|CNMD_HUMAN GRLNNETRPSVQEDSQAFNPDNPYHQQEGESMTFDPRLDHEGICCIECR---RSYTHCQK 295 * $\quad . \quad::^{\star \star}:::: \quad:: .{ }^{\star}: . .^{\star}:{ }^{\star} \quad .^{\star}{ }^{\star}$

SP|014960|LECT2 HUMAN KGEKLGTLLPLQKVYPGIQSHVHIENCDSSDPTAYL-------- 151 SP|O75829|CNMD_HUMAN ICEPLGGYYPWPYNYQGCRSA-----CRVIMPCSWWVARILGMV 334

$$
\star \star \star \star \star * \star: \star * \star *:
$$


४Fig. 1 Multiple sequence alignment showing substantial identity among Chm-1 amino acid sequences in human, mouse, rat, bovine, and rabbit, with a consensus potential glycosylation site underlined, and a putative furin cleavage site (RERR) in bold font (a). Multiple sequence alignment showing limited homology between human Chm-1 (LECT1) and chondromodulin-II (LECT2) amino acid sequence at their C-terminal regions (b)

\section{Molecular structure, gene expression, and function of $\mathrm{Chm}-1$}

The human chondromodulin-1 gene (Chm-1, or Chm-I), also referred to as CNMD, leukocyte cell-derived chemotaxin 1, or Lect 1 is located on chromosome 13q14-21, and encodes a 334 amino acid type II transmembrane glycoprotein. Multiple sequence alignment indicates that inter-species sequence homology among human, mouse, rat, bovine and rabbit Chm-1 homologs is conserved, by approximately $90 \%$ amino acid sequence identity between species homologs (Fig. 1a). Chm-1 only shares limited sequence similarity with chondromodulin-II (or Lect2) at the C-terminus (Fig. 1b). Protein sequence analyses indicate that human $\mathrm{Chm}-1$ contains a transmembrane domain between amino acid residues 40-65, a furin cleavage site (RERR) at amino acid residue 215 , and an $\mathrm{N}$-linked glycosylation site (NET) at amino acid residue 243 (Fig. 2a). The Chm-1 protein also consists of a BRICHOS domain from amino acid residues 104-210, that is referred to as lung surfactant protein $\mathrm{C}$ proprotein (proSPC), although its biological activity is yet to be experimentally examined (Fig. 2a). Tertiary structure analysis reveals that the Chm-1 protein features a typical helical conformation, based on the Phyre 2 protein modelling web portal, and by RaptorX template-based protein structure modelling, respectively (Fig. 2b, c) [11-13].

Further structural and functional analyses indicate that Chm- 1 encodes a type II transmembrane glycoprotein, which was detected in two forms [8]. A $14 \mathrm{kDa}$ species was generated by proteolytic cleavage at Asp37-Asp38 at the N-terminus, which appears to have little or no inhibitory antiangiogenic activity, and to be located in the hypertrophic and calcified zones. By comparison, the intact $20-25 \mathrm{kDa}$ species was predominantly detected in the avascular zones, including resting, proliferating, and pre-hypertrophic zones of developing long bones [8]. The intact $\mathrm{Chm}-1$ protein is abundantly expressed in the inner meniscus of the knee, and appears to be an anti-angiogenic factor that is important for maintaining the avascularity of the inner meniscus by inhibiting endothelial cell proliferation [14]. During endochondral ossification, Chm-1 is expressed in the avascular zone of cartilage, but not calcifying cartilage, and appears to prevent vascular invasion during bone formation [2]. Chm-1 is sensitive to furin-mediated cleavage and the mature form of human Chm-1 is present in the cell culture supernatant, which is indicative of its secretory nature $[15,16]$. Further, the C-terminus of the mature, secreted, intact form of Chm1 , exerts anti-angiogenic and anti-tumour activities, and bears similar function and homology to the C-terminal domain of the tenomodulin (TeM) glycoprotein [10]. Interestingly, chondromodulin-II (or Lect2), which shares limited sequence homology at the C-terminus with Chm-1, is a component protein of cartilage matrix that promotes chondrocyte proliferation during endochondral ossification [17].

Chm-1 mRNA is expressed most abundantly in avascular cartilage and cardiac valves, and has been shown to promote chondrocyte differentiation and to inhibit angiogenesis by endothelial cell-mediated tubule formation $[1,2$, $4,14]$. Chm-1 is also expressed in the CD31(-) avascular mesenchyme and eyes $[18,19]$. The differential expression pattern of Chm-1 mRNA and tenomodulin (TeM) mRNA was compared in mandibular condylar cartilage and tibial cartilage, with Chm-1 mRNA less abundant in mandibular condylar cartilage than in tibial as compared to TeM mRNA [20]. A number of studies have shown that its expression appears to be regulated by transcription factors Sox $9, \mathrm{Sp} 3$, histone modifiers (YY1 and p300), and Pax1 and Nk3 homeobox 2 (Nkx3.2) [21-24]. Chm-1 appears to maintain cartilage homeostasis by inhibiting hypoxia-inducible factor- $2 \alpha$ (HIF-2 $\alpha$ ) induced catabolic activity, and may be a potential therapeutic target for the inhibition of cartilage degradation resulting from osteoarthritis [25].

Utilising Genevisible ${ }^{\circledR}$ gene profiling analyses, Chm-1 mRNA expression is detected in human and mouse, tissues and cell lines [26]. Chm-1 mRNA appears to be most abundantly expressed in human growth plate, human foetal retina pigment epithelium cells, and human embryo tissues, and mouse ovarian granulosa cell, mouse embryonic vertebrae, and mouse stria vascularis tissues (Fig. 3). In addition, Chm-1 mRNA is expressed in human and mouse cell lines. Chm-1 mRNA most abundantly expressed in the iPS.C2a, hiPS 1-8, and MRC5- iPS2 human cell lines, and the PyMT, $\mathrm{C} 3 \mathrm{H} / 10 \mathrm{~T} 1 / 2$ clone 8 -TetR-Tbx 5 , and $\mathrm{C} 3 \mathrm{H} / 10 \mathrm{~T} 1 / 2$ clone 8 mouse cell lines (Fig. 4).

\section{The effect of Chm-1 in cartilage and osteoarthritis (OA) progression}

Several lines of evidence suggest that $\mathrm{Chm}-1$ is involved in the regulation of chondrocyte differentiation and cartilage homeostasis [25, 27-30]. In vitro findings suggest that Chm-1 promotes the growth of chondrocytes via an autocrine signalling mechanism in the presence of fibroblast growth factor 2 (FGF-2) [31]. Targeted disruption of the Chm-1 gene showed no obvious phenotypic abnormality of endochondral bone formation during embryogenesis or cartilage development during growth stages of $\mathrm{Chm}-1(-/-)$ mice $[6,30]$. Interestingly, adult $\mathrm{Chm}-1(-/-)$ mice showed an 
Fig. 2 Molecular structure of Chm-1. Secondary structure of Chm-1 showing that it contains a transmembrane domain between amino acid residues 40-65, a furin cleavage site (RERR) at 215 amino acid residue, an N-linked glycosylation site (NET) at 243 amino acid residue, and a BRICHOS domain from 104-210 amino acid residues (a). Tertiary structure analysis reveals that it features a typical helical conformation based on the Phyre2 web portal for protein modelling (http://twitter.com/phyre 2server) (b), and by RaptorX template-based protein structure modelling (http://raptorx.uchic ago.edu/StructurePrediction) (c)

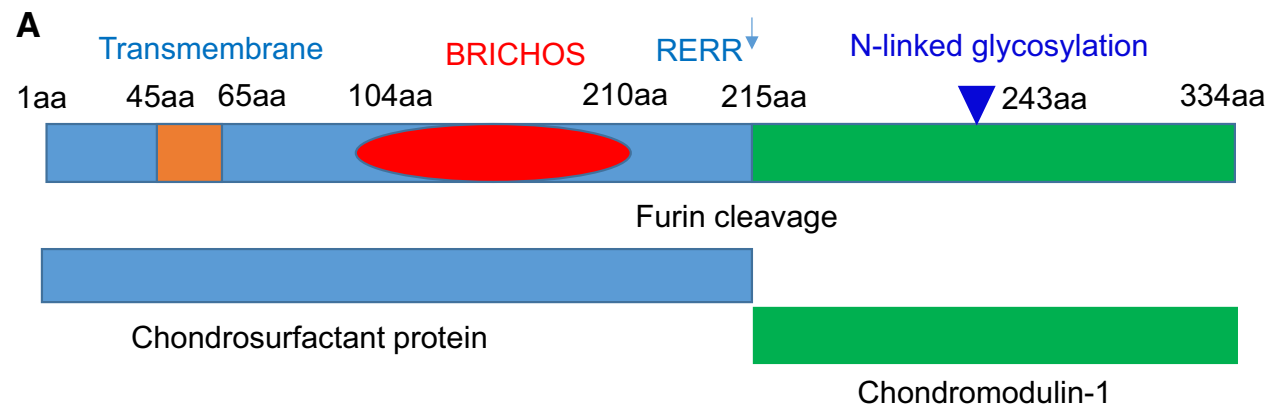

B

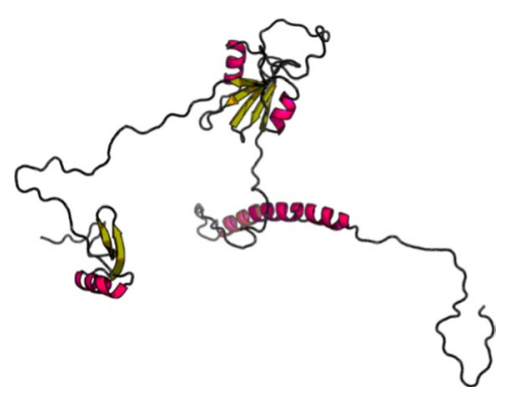

C

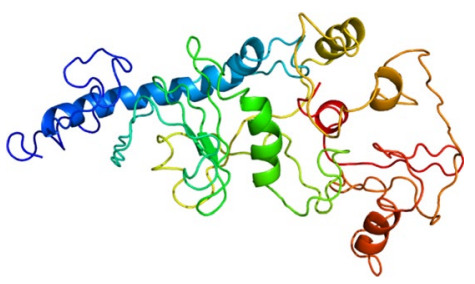

increased bone mineral density phenotype, with decreased bone resorption, indicating that $\mathrm{Chm}-1$ may also be an important factor for bone remodelling and metabolism [6]. Notably, Chm-1 gene knockout directly restricted ectopic cartilage regeneration in vivo and inhibited ectopic stability of regenerated cartilage in vitro, suggesting that $\mathrm{Chm}-1$ plays a role in ectopic cartilage regeneration and cartilage homeostasis [30]. Since Chm-1 appears to be an important factor for the maintenance of cartilage homeostasis and bone metabolism, the effect of Chm-1 knockout on bone repair was tested [5]. Findings from this study indicate that the healing following bone fracture is delayed in $\mathrm{Chm}-1(-/-)$ mice, which appears to be the result of impaired periosteal chondrocyte differentiation and reduced cartilaginous callus formation during the healing process [5]. Collectively, these findings indicate that $\mathrm{Chm}-1$ is an important factor for chondrocyte maturation and cartilage homeostasis, and could be involved in bone remodelling and repair.

Articular cartilage is an avascular tissue that is composed of extracellular matrix and sparsely populated by chondrocytes, thus providing a smooth, lubricated surface for the function of diarthrodial joints [32]. Osteoarthritis (OA) is a chronic joint disease characterized by cartilage destruction, subchondral bone sclerosis, and osteophyte formation, which appear to be accompanied by vascular invasion of the articular cartilage [33, 34]. Decreased expression of Chm-1 was found to be associated with the onset and progression of OA [35]. The loss of Chm-1 protein function may exacerbate OA progression due to the loss of anti-angiogenic activity of Chm-1, and the subsequent vascular invasion of articular cartilage, which may be accompanied by chondrocyte hypertrophy $[25,35]$. HIF- $2 \alpha$ appears to cause OA cartilage destruction via matrix degradation, chondrocyte apoptosis, and an angiogenic signalling cascade [25, 36]. Induced expression of $\mathrm{Chm}-1$ was found to mitigate OA progression via attenuating HIF- $2 \alpha$ nuclear translocation and transcriptional activity [25]. In addition, Chm-1 overexpression appears to reduce tumour necrosis factor alpha (TNF- $\alpha$ ) induced chondrocyte hypertrophy, and in vivo intra-articular administration of LV-Chm-1 appears to slow OA progression [25]. Further, thinning of the articular cartilage and the appearance of a vascular channel resulting from immobilization-induced OA cartilage degradation is associated with reduced expression of Chm-1, and increased expression of HIF-1 $\alpha$ and vascular endothelial growth factor (VEGF) [37]. Chm-1 appears to stabilize the chondrocyte phenotype by supporting chondrogenesis, whilst inhibiting chondrocyte hypertrophy and aberrant endochondral ossification during cartilage tissue repair, which is accompanied by the upregulation of the cell cycle inhibitor p21WAF1/Cip1 [29]. Collectively, these findings suggest that Chm-1 plays a role in the regulation of chondrocyte differentiation and maturation, in the protection from the onset and progression of osteoarthritis, and is involved in the regulation of cartilage repair.

Recently, the significance of Chm-1 expression associated with angiogenesis during the pathogenesis of temporomandibular joint (TMJ) osteoarthritis was investigated [38]. $\mathrm{Chm}-1$ protein expression was observed in the proliferative and hypertrophic zone of mandibular condylar cartilage, and chondrocyte-like cells in the TMJ disc by immunohistochemistry analyses; which is indicative of a role of Chm-1 in the regulation of TMJ remodelling via preventing blood vessel invasion of the condylar cartilage and by maintaining the integrity of the condylar cartilage and TMJ disc [28]. Lack 
A

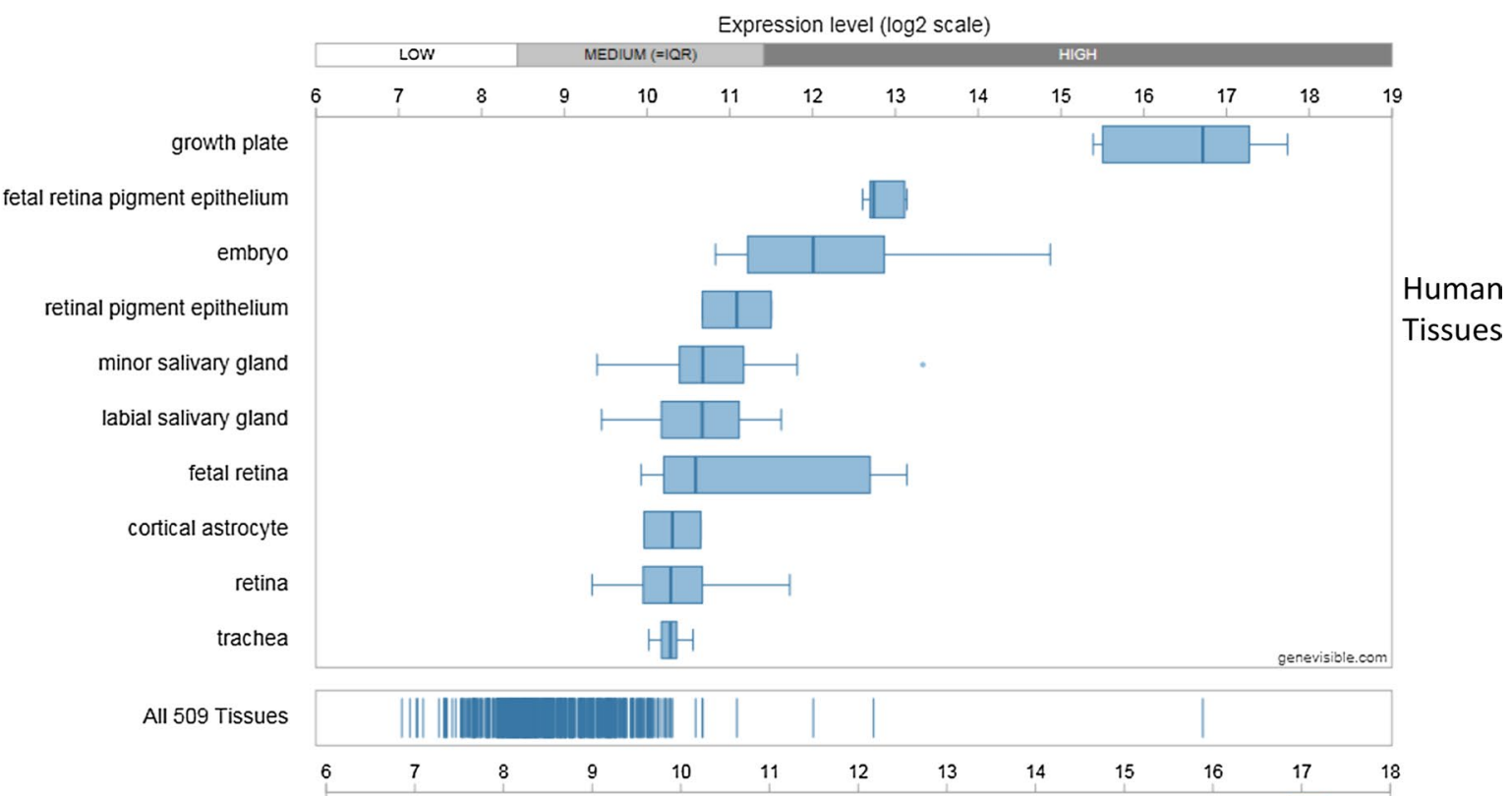

B

$$
\begin{array}{r}
\text { ovarian granulosa cell } \\
\text { embryonic vertebrae } \\
\text { stria vascularis } \\
\text { embryonic chondrocyte }
\end{array}
$$

embryonic skeletal system (except bone marrow)

embryonic intervertebral disc

cochlea

ovary (female gonad)

$$
\text { ear }
$$

All 469 Tissues

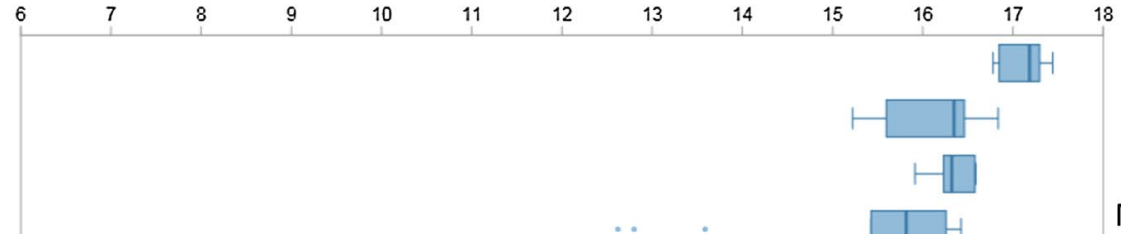

Mouse

Tissues

Fig. 3 Expression analyses showing the Chm-1 expression in both human (a) and mouse (b) tissues, with 10 most highly expressed tissues for each species, performed by Genevisible ${ }^{\circledR}$ (http://genevisible.com)

of expression of Chm-1 in deep hypertrophic chondrocytes may result in vascular invasion of the condylar cartilage and lead to TMJ osteoarthritis [34].

The anti-angiogenic and chondrogenic properties of Chm-1 have been utilised for potential bioengineering applications. Interestingly, the inhibition of vascular ingrowth by the upregulation of $\mathrm{Chm}-1$ on platelet-rich plasma (PRP)/ hydrogel composites, provided an improved microenvironment for the regeneration of hyaline cartilage [39]. Further, the chondrogenic phenotype of marrow mesenchymal stem cell (MSC)-cartilage grafts may be stabilized by Chm-1 gene-modification leading to improved success of MSCcartilage grafts; and the chondrogenesis and cartilage regenerative potential of MSCs may be enhanced by Chm-1 gene transfection [40, 41]. Taken together, these results indicate that the genetic modulation of Chm-1 in relation to chondrogenesis and cartilage regeneration may be a potential therapeutic strategy for osteoarthritis treatment by the improvement of regenerative tissue engineering applications.

\section{The role of $\mathrm{Chm}-1$ in cancer and heart disease}

The role of Chm-1 in cancers is largely unknown. The antiangiogenic properties of Chm-1 are postulated to inhibit tumour growth, propagation, and metastasis, indicating that loss of Chm-1 function may induce tumorigenesis [42]. Significantly, Chm-1 appears to be implicated in the pathogenesis of the two most common childhood bone tumours, 


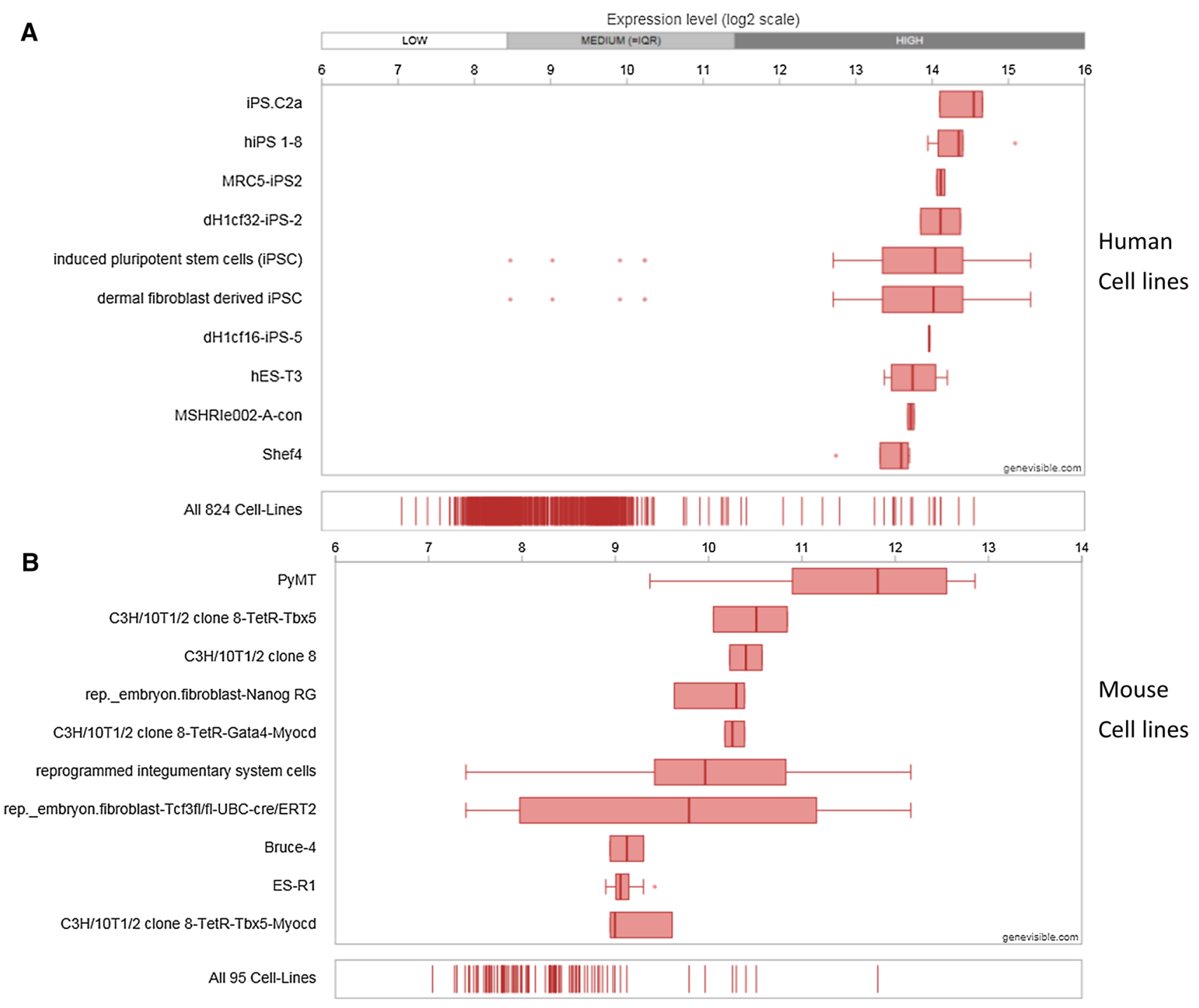

Fig. 4 Expression analyses showing the Chm-1 expression in both human (a) and mouse (b) cell lines, with 10 most highly expressed cell lines for each species, performed by Genevisible ${ }^{\circledR}$ (http://genevisible.com)

osteosarcoma and Ewing's sarcoma (ES) [42, 43]. Chm-1 has been shown to inhibit the growth and proliferation of human osteosarcoma cells in vivo, and to inhibit the invasion and migration of human osteosarcoma cells in vitro [42]. Further research is necessary to investigate the properties and mechanisms by which Chm-1 could inhibit osteosarcoma tumorigenesis, and to develop the therapeutic potential of Chm-1 for the treatment of osteosarcoma. Chm-1 was found to be overexpressed in ES (the second most common childhood bone malignancy), which appears to be regulated by oncogenic fusion protein chimeric transcription factor, EWS-FLI1 [43]. Chm-1 could enhance the invasive potential of ES cells in vitro, and may promote ES lung metastases in vivo via the regulation of matrix metalloproteinase 9 (MMP9) expression [43]. Chm-1 appears to promote the malignancy of ES by maintaining its immature chondrocytic phenotype [43]. Further, although Chm-1 appears to inhibit endothelial differentiation in vitro and in vivo, no difference in angiogenesis was observed for in vivo tumour samples, suggesting that modulation of angiogenesis by $\mathrm{Chm}-1$ does not appear to enhance ES metastasis [43]. As an enhancer of ES malignancy, Chm-1 is a prime therapeutic target warranting further investigation. $\mathrm{Chm}-1$ directed allorestricted T-cell receptor (TCR) transgenic CD8+ T cells have been developed and demonstrate the capacity to specifically inhibit ES growth in vitro and in vivo [44]. Moreover, clinical research shows that $\mathrm{Chm}$-1-specific allorestricted T-cell receptor (TCR) transgenic $\mathrm{T}$ cells home to bone marrow metastases and may cause partial disease regression without graft versus host disease (GvHD) in ES patients, indicating the need for future clinical trials [45]. Taken together, these findings suggest that the role of Chm-1 in the pathogenesis 
of ES appears to be pleiotropic, indicating the need for further investigation, and development of the potential of Chm-1 as a therapeutic target for ES [43]. Additionally, Chm-1 expression was shown to be downregulated in gastric cancer, and Chm-1 appears to be a potential tumour suppressor, that may also be an important biomarker for the treatment and prognosis of gastric cancer [46]. Chm-1 is also differentially expressed between benign and malignant (thyroid carcinomas) tumours of patients with multiple endocrine neoplasia (MEN), thus providing molecular evidence for the skeletal abnormalities and malignancy of different forms of MEN [47]. Chm-1 expression was also detected in lacuna cells and neoplastic myoepithelial cells during the pathogenesis of pleomorphic adenoma, which is indicative of its involvement in the hypo-vascularity and chondroid formation of pleomorphic adenoma [48]. At the cellular level, Chm-1 appears to be capable of exhibiting a dual role by promoting cell proliferation and suppressing the growth of tumour cells in a dose-dependent relationship [49]. Low concentrations of Chm-1 appear to promote osteoblastic-cell growth, whereas higher concentrations of $\mathrm{Chm}-1$ suppressed the growth and migration of tumour cells, such as human cervical cancer (HeLa) cells and human neuroblastoma (SH-SY5Y) cells, and inhibited the proliferation and angiogenesis of human umbilical vein endothelial cells (HUVECs) [49]. Reports suggest that the anti-angiogenic properties of Chm-1 may contribute to the inhibitory effect of tumour progression $[50,51]$. Chm- 1 exerts a direct antitumour effect by inhibiting the STAT signalling pathway [50]. Mechanistic studies revealed that $\mathrm{Chm}-1$ can induce human nasopharyngeal carcinoma (NPC) cell apoptosis by inhibiting the formation of the cell surface-associated endoplasmic reticulum chaperone glucose-regulated protein 78 (GRP78)-phosphatidylinositol 3-kinase-protein kinase B (PI3K-AKT) signalling complex [52]. Chm-1 also appears to be capable of inhibiting the growth of breast cancer cells by modulating the expression levels of cell cycle associated genes, and thus may have potential clinical applications for the treatment of breast cancer [53]. Collectively, these findings suggest a role for Chm-1 in the pathogenesis of a variety of cancers, which appears to be related to the regulation of chondrocytic differentiation and anti-angiogenic properties of Chm-1, thus indicating the need for further investigation. The cellular and molecular signalling pathways involved in cancer pathogenesis of $\mathrm{Chm}-1$ are largely unknown and require further testing. The role of $\mathrm{Chm}-1$ in cancer pathogenesis warrants further investigation to develop its potential as a therapeutic target for cancer treatment.

Inflammation-induced neo-vascularization is a pathogenic hallmark in the development of infective endocarditis (IE). Chm-1 expression is downregulated in valvular tissues at the early phase of IE, which might lead to leaflet vascularization and the progression of endocarditis, likely by a combination of the reduced anti-angiogenic resistance of leaflets and the immune-mediated inflammatory response resulting from decreased Chm-1 levels $[54,55]$. The antiangiogenic properties of $\mathrm{Chm}-1$ that protect cardiac valves from pathological vascularization, may be attributed to the regulation of angiogenesis and matrix metalloproteinases $[56,57]$. Further, hypoxia-associated reduced expression of Chm-1 might also be a factor for mid-to-late valve disease progression [58]. During implantation, Chm-1 was shown to have an inhibitory effect on trophoblast migration and invasion, which implies that Chm-1 may affect the regulation of tissue differentiation and angiogenesis during embryonic development [59]. Further studies are required to advance our understanding of the role of Chm-1 in the development of infective endocarditis, and embryogenesis.

\section{Chm-1 receptor and signalling}

The receptor for Chm-1 is not known. In a study of human nasopharyngeal carcinoma cells (NPC), $\mathrm{Chm}-1$ was found to induce NPC cell apoptosis by inhibiting the formation of the cell surface-associated endoplasmic reticulum chaperone GRP78-PI3K-AKT signalling complex [52]. The downstream effects of PI3K/AKT signalling might affect the mTOR network, responsible for cell survival. The direct tumour cell suppressing effect of Chm-1 appears to be mediated by its inhibition of the STAT signalling cascade [50]. Further studies are required to identify and characterize the Chm-1 receptor and its subsequent activity on key downstream signalling pathways. For example, in the perforated disks of temporomandibular joint (TMJ), angiogenesis appears to be regulated by factors that induce the NF- $\mathrm{BB}$ pathway [60]. Chm-1 expression was found to be significantly lower in perforated disks as compared to healthy disks, which appears to be regulated via the NF- $\kappa B$ pathway in the presence of interleukin- $1 \beta$ (IL-1 $\beta$ ), linking $\mathrm{Chm}-1$ to receptor-mediated NF- $\mathrm{kB}$ signaling and pathological angiogenesis of the TMJ [60]. Future studies to identify the specific receptor for $\mathrm{Chm}-1$, and to determine the subsequent effect of signalling activation in a cell type dependent manner, are necessary to design therapeutic approaches for the treatment of Chm-1 related conditions, including osteoarthritis, infective endocarditis, and cancer.

\section{Summary and conclusion}

Expression profiling indicates that $\mathrm{Chm}-1$ is predominantly expressed in healthy and developing avascular cartilage, particularly during endochondral ossification, and in healthy cardiac valves (Fig. 5). Chm-1 plays a key role in chondrogenesis, chondrocyte maturation, and cartilage homeostasis. 
Fig. 5 A hypothetical working model of Chm-1. a Chm-1 gene is expressed by many cell types and tissues such as avascular cartilage cells, cardiac valves, growth plate, foetal retina pigment epithelium cells, embryo tissue, ovarian granulosa cells, embryonic vertebrae, and stria vascularis tissues. Its expression is regulated by transcription factors including Sox9, Sp3, YY1, p300, Pax1, and Nkx3.2. b Precursor Chm-1, as a type II transmembrane glycoprotein protein is cleaved by furin to release its mature $\mathrm{Chm}-1$. Mature Chm-1 binds to an unknown receptor in a cell type dependent manner and mediates downstream signalling cascades such as GRP78-PI3K-AKT and mTOR signalling for cell survival, Stat signalling for tumour cell suppression, and HIF- $2 \alpha$ signalling for angiogenesis and chondrogenesis
A

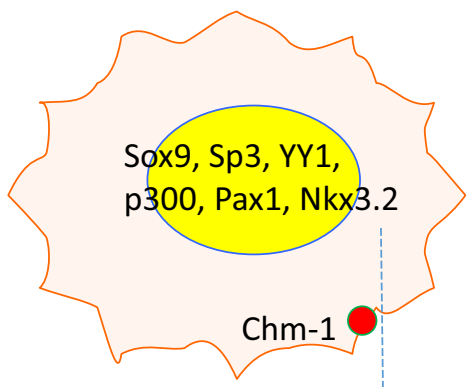

Avascular cartilage cells

Cardiac valves cells

Growth plate

Foetal retina pigment epithelium cells

Embryo tissues

Ovarian granulosa cell

Embryonic vertebrae

Stria vascularis tissues

Chm-1 as a type II membrane protein is cleaved by Furin

\section{B}
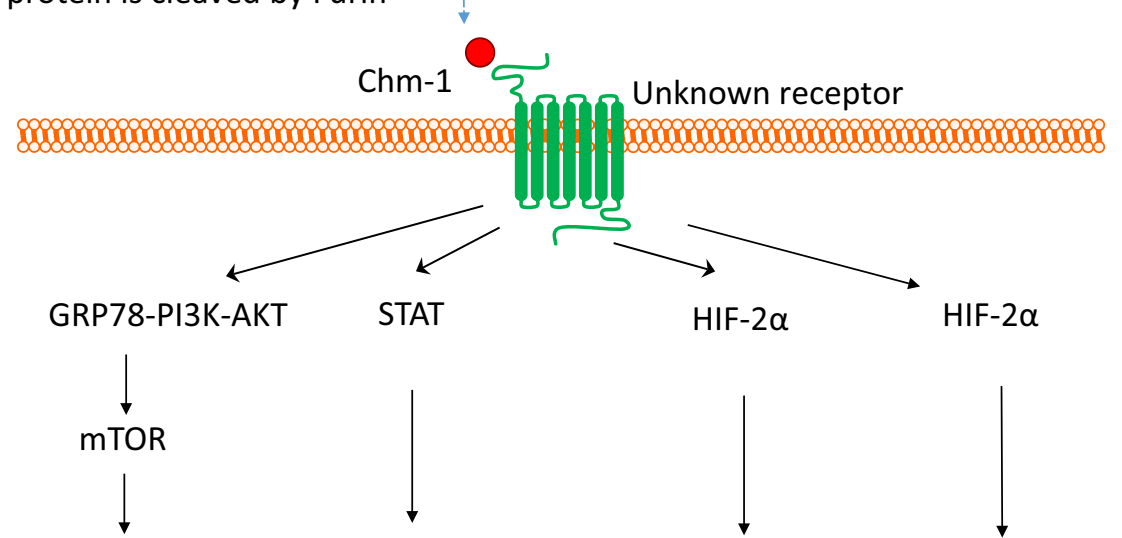

Cell survival
Decreased Chm-1 activity is implicated in the onset and progression of diseases, including osteoarthritis, infective endocarditis, and cancers. The anti-angiogenic and immune regulatory properties of Chm-1 are attributed to its role in disease prevention. The expression of Chm-1 appears to be regulated by several transcription factors, including Sox9, Sp3, YY1, p300, Pax1, and Nkx3.2. The Chm-1 receptor and downstream signalling effects remain largely unknown. Overall, Chm-1 represents a promising potential target for the delivery of therapeutic and bioengineering regenerative applications. Further research to elucidate the molecular mechanistic roadmap of Chm-1 will assist us to develop a therapeutic strategy for the treatment of diseases, such as osteoarthritis, infective endocarditis, and cancer.

Acknowledgements This work was partly supported by a research grant from the National Natural Science Funding of China (81802235), Zhejiang Experimental Animal Science and Technology Project of China (2018C37112), and Wenzhou basic science research plan project (Y20180033), which in part support Dr. Sipin Zhu as a visiting scholar to UWA from Wenzhou Medical University. Dr. Sipin Zhu and Jiake Xu made mutual collaborative visits in 2017. This study was supported in part by the Australian National Health and Medical Research Council (NHMRC, APP1107828, APP1127156, APP1163933). Professor Vicki Rosen was a Raine Visiting Professor and an Australia-Harvard Fellow at Jiake Xu's UWA laboratory.

\section{Compliance with ethical standards}

Conflict of interest All authors declare that they have no conflict of interest.

Open Access This article is distributed under the terms of the Creative Commons Attribution 4.0 International License (http://creativeco mmons.org/licenses/by/4.0/), which permits unrestricted use, distribution, and reproduction in any medium, provided you give appropriate credit to the original author(s) and the source, provide a link to the Creative Commons license, and indicate if changes were made.

\section{References}

1. Hiraki Y, Tanaka H, Inoue H, Kondo J, Kamizono A, Suzuki F (1991) Molecular cloning of a new class of cartilage-specific matrix, chondromodulin-I, which stimulates growth of cultured chondrocytes. Biochem Biophys Res Commun 175:971-977

2. Hiraki Y, Inoue H, Iyama K, Kamizono A, Ochiai M, Shukunami C, Iijima S, Suzuki F, Kondo J (1997) Identification of chondromodulin I as a novel endothelial cell growth inhibitor. Purification and its localization in the avascular zone of epiphyseal cartilage. J Biol Chem 272:32419-32426

3. Hayami T, Shukunami C, Mitsui K, Endo N, Tokunaga K, Kondo J, Takahashi HE, Hiraki Y (1999) Specific loss of chondromodulin-I gene expression in chondrosarcoma and the suppression of tumor angiogenesis and growth by its recombinant protein in vivo. FEBS Lett 458:436-440

4. Yoshioka M, Yuasa S, Matsumura K, Kimura K, Shiomi T, Kimura N, Shukunami C, Okada Y, Mukai M, Shin H, Yozu R, Sata M, Ogawa S, Hiraki Y, Fukuda K (2006) Chondromodulin-I 
maintains cardiac valvular function by preventing angiogenesis. Nat Med 12:1151-1159. https://doi.org/10.1038/nm1476

5. Yukata K, Matsui Y, Shukunami C, Takimoto A, Goto T, Nishizaki Y, Nakamichi Y, Kubo T, Sano T, Kato S, Hiraki Y, Yasui $\mathrm{N}$ (2008) Altered fracture callus formation in chondromodulin-I deficient mice. Bone 43:1047-1056. https://doi.org/10.1016/j. bone.2008.08.111

6. Nakamichi Y, Shukunami C, Yamada T, Aihara K, Kawano H, Sato T, Nishizaki Y, Yamamoto Y, Shindo M, Yoshimura K, Nakamura T, Takahashi N, Kawaguchi H, Hiraki Y, Kato S (2003) Chondromodulin I is a bone remodeling factor. Mol Cell Biol 23:636-644

7. Shukunami C, Hiraki Y (2001) Role of cartilage-derived antiangiogenic factor, chondromodulin-I, during endochondral bone formation. Osteoarthr Cartil 9(Suppl A):S91-S101

8. Miura S, Kondo J, Takimoto A, Sano-Takai H, Guo L, Shukunami C, Tanaka H, Hiraki Y (2014) The N-terminal cleavage of chondromodulin-I in growth-plate cartilage at the hypertrophic and calcified zones during bone development. PLoS One 9:e94239. https://doi.org/10.1371/journal.pone.0094239

9. Shukunami C, Takimoto A, Miura S, Nishizaki Y, Hiraki Y (2008) Chondromodulin-I and tenomodulin are differentially expressed in the avascular mesenchyme during mouse and chick development. Cell Tissue Res 332:111-122. https://doi.org/10.1007/s0044 1-007-0570-8

10. Oshima Y, Sato K, Tashiro F, Miyazaki J, Nishida K, Hiraki Y, Tano Y, Shukunami C (2004) Anti-angiogenic action of the C-terminal domain of tenomodulin that shares homology with chondromodulin-I. J Cell Sci 117:2731-2744. https://doi.org/10.1242/ jcs.01112

11. Kallberg M, Margaryan G, Wang S, Ma J, Xu J (2014) RaptorX server: a resource for template-based protein structure modeling. Methods Mol Biol 1137:17-27. https://doi. org/10.1007/978-1-4939-0366-5_2

12. Kallberg M, Wang H, Wang S, Peng J, Wang Z, Lu H, Xu J (2012) Template-based protein structure modeling using the RaptorX web server. Nat Protoc 7:1511-1522. https://doi.org/10.1038/ nprot.2012.085

13. Kelley LA, Mezulis S, Yates CM, Wass MN, Sternberg MJ (2015) The Phyre2 web portal for protein modeling, prediction and analysis. Nat Protoc 10:845-858. https://doi.org/10.1038/nprot.2015.053

14. Fujii M, Furumatsu T, Yokoyama Y, Kanazawa T, Kajiki Y, Abe N, Ozaki T (2013) Chondromodulin-I derived from the inner meniscus prevents endothelial cell proliferation. J Orthop Res 31:538-543. https://doi.org/10.1002/jor.22257

15. Azizan A, Holaday N, Neame PJ (2001) Post-translational processing of bovine chondromodulin-I. J Biol Chem 276:2363223638. https://doi.org/10.1074/jbc.M009967200

16. Hiraki Y, Mitsui K, Endo N, Takahashi K, Hayami T, Inoue H, Shukunami C, Tokunaga K, Kono T, Yamada M, Takahashi HE, Kondo J (1999) Molecular cloning of human chondromodulin-I, a cartilage-derived growth modulating factor, and its expression in Chinese hamster ovary cells. Eur J Biochem 260:869-878

17. Hiraki Y, Inoue H, Kondo J, Kamizono A, Yoshitake Y, Shukunami C, Suzuki F (1996) A novel growth-promoting factor derived from fetal bovine cartilage, chondromodulin II. Purification and amino acid sequence. J Biol Chem 271:22657-22662

18. Shukunami C, Yoshimoto Y, Takimoto A, Yamashita H, Hiraki Y (2016) Molecular characterization and function of tenomodulin, a marker of tendons and ligaments that integrate musculoskeletal components. Jpn Dent Sci Rev 52:84-92. https://doi. org/10.1016/j.jdsr.2016.04.003

19. Fukushima A, Funaki H, Yaoeda K, Tanaka T, Shirakashi M, Yoshida Y, Yaoita E, Abe H, Yamamoto T (2003) Localization and expression of chondromodulin-I in the rat cornea. Arch Histol Cytol 66:445-452
20. Watahiki J, Yamaguchi T, Enomoto A, Irie T, Yoshie K, Tachikawa T, Maki K (2008) Identification of differentially expressed genes in mandibular condylar and tibial growth cartilages using laser microdissection and fluorescent differential display: chondromodulin-I (ChM-1) and tenomodulin (TeM) are differentially expressed in mandibular condylar and other growth cartilages. Bone 42:1053-1060. https://doi.org/10.1016/j.bone.2007.09.048

21. Takimoto A, Oro M, Hiraki Y, Shukunami C (2012) Direct conversion of tenocytes into chondrocytes by Sox9. Exp Cell Res 318:1492-1507. https://doi.org/10.1016/j.yexcr.2012.04.002

22. Aoyama T, Okamoto T, Nagayama S, Nishijo K, Ishibe T, Yasura K, Nakayama T, Nakamura T, Toguchida J (2004) Methylation in the core-promoter region of the chondromodulin-I gene determines the cell-specific expression by regulating the binding of transcriptional activator Sp3. J Biol Chem 279:28789-28797. https://doi.org/10.1074/jbc.M401273200

23. Aoyama T, Okamoto T, Fukiage K, Otsuka S, Furu M, Ito K, Jin Y, Ueda M, Nagayama S, Nakayama T, Nakamura T, Toguchida J (2010) Histone modifiers, YY1 and p300, regulate the expression of cartilage-specific gene, chondromodulin-I, in mesenchymal stem cells. J Biol Chem 285:29842-29850. https://doi. org/10.1074/jbc.M110.116319

24. Takimoto A, Mohri H, Kokubu C, Hiraki Y, Shukunami C (2013) Pax 1 acts as a negative regulator of chondrocyte maturation. Exp Cell Res 319:3128-3139. https://doi.org/10.1016/j.yexcr .2013.09.015

25. Zhang X, Prasadam I, Fang W, Crawford R, Xiao Y (2016) Chondromodulin-1 ameliorates osteoarthritis progression by inhibiting HIF-2alpha activity. Osteoarthr Cartil 24:1970-1980. https://doi. org/10.1016/j.joca.2016.06.005

26. Hruz T, Laule O, Szabo G, Wessendorp F, Bleuler S, Oertle L, Widmayer P, Gruissem W, Zimmermann P (2008) Genevestigator v3: a reference expression database for the meta-analysis of transcriptomes. Adv Bioinform 2008:420747. https://doi. org/10.1155/2008/420747

27. Yanagihara I, Yamagata M, Sakai N, Shukunami C, Kurahashi H, Yamazaki M, Michigami T, Hiraki Y, Ozono K (2000) Genomic organization of the human chondromodulin-1 gene containing a promoter region that confers the expression of reporter gene in chondrogenic ATDC5 cells. J Bone Miner Res 15:421-429. https ://doi.org/10.1359/jbmr.2000.15.3.421

28. Fang W, Friis TE, Long X, Xiao Y (2010) Expression of chondromodulin-1 in the temporomandibular joint condylar cartilage and disc. J Oral Pathol Med 39:356-360. https://doi.org/10.111 1/j.1600-0714.2009.00831.x

29. Klinger P, Surmann-Schmitt C, Brem M, Swoboda B, Distler JH, Carl HD, von der Mark K, Hennig FF, Gelse K (2011) Chondromodulin 1 stabilizes the chondrocyte phenotype and inhibits endochondral ossification of porcine cartilage repair tissue. Arthritis Rheum 63:2721-2731. https://doi.org/10.1002/art.30335

30. Zhu Y, Zhang Y, Liu Y, Tao R, Xia H, Zheng R, Shi Y, Tang S, Zhang W, Liu W, Cao Y, Zhou G (2015) The influence of Chm-I knockout on ectopic cartilage regeneration and homeostasis maintenance. Tissue Eng Part A 21:782-792. https://doi.org/10.1089/ ten.TEA.2014.0277

31. Inoue H, Kondo J, Koike T, Shukunami C, Hiraki Y (1997) Identification of an autocrine chondrocyte colony-stimulating factor: chondromodulin-I stimulates the colony formation of growth plate chondrocytes in agarose culture. Biochem Biophys Res Commun 241:395-400. https://doi.org/10.1006/bbrc.1997.7820

32. Sophia Fox AJ, Bedi A, Rodeo SA (2009) The basic science of articular cartilage: structure, composition, and function. Sports Health 1:461-468. https://doi.org/10.1177/1941738109350438

33. Hayami T, Pickarski M, Zhuo Y, Wesolowski GA, Rodan GA, Duong LT (2006) Characterization of articular cartilage and subchondral bone changes in the rat anterior cruciate ligament 
transection and meniscectomized models of osteoarthritis. Bone 38:234-243. https://doi.org/10.1016/j.bone.2005.08.007

34. Wang QY, Dai J, Kuang B, Zhang J, Yu SB, Duan YZ, Wang MQ (2012) Osteochondral angiogenesis in rat mandibular condyles with osteoarthritis-like changes. Arch Oral Biol 57:620-629. https ://doi.org/10.1016/j.archoralbio.2011.12.006

35. Hayami T, Funaki H, Yaoeda K, Mitui K, Yamagiwa H, Tokunaga K, Hatano H, Kondo J, Hiraki Y, Yamamoto T, Duong LT, Endo N (2003) Expression of the cartilage derived anti-angiogenic factor chondromodulin-I decreases in the early stage of experimental osteoarthritis. J Rheumatol 30:2207-2217

36. Ryu JH, Shin Y, Huh YH, Yang S, Chun CH, Chun JS (2012) Hypoxia-inducible factor-2alpha regulates Fas-mediated chondrocyte apoptosis during osteoarthritic cartilage destruction. Cell Death Differ 19:440-450. https://doi.org/10.1038/cdd.2011.111

37. Sakamoto J, Origuchi T, Okita M, Nakano J, Kato K, Yoshimura T, Izumi S, Komori T, Nakamura H, Ida H, Kawakami A, Eguchi K (2009) Immobilization-induced cartilage degeneration mediated through expression of hypoxia-inducible factor-1alpha, vascular endothelial growth factor, and chondromodulin-I. Connect Tissue Res 50:37-45. https://doi.org/10.1080/03008200802412454

38. Liu J, Dai J, Wang Y, Lai S, Wang S (2017) Significance of new blood vessels in the pathogenesis of temporomandibular joint osteoarthritis. Exp Ther Med 13:2325-2331. https://doi. org/10.3892/etm.2017.4234

39. Lee HR, Park KM, Joung YK, Park KD, Do SH (2012) Plateletrich plasma loaded in situ-formed hydrogel enhances hyaline cartilage regeneration by CB1 upregulation. J Biomed Mater Res A 100:3099-3107. https://doi.org/10.1002/jbm.a.34254

40. Chen Z, Wei J, Zhu J, Liu W, Cui J, Li H, Chen F (2016) Chm-1 gene-modified bone marrow mesenchymal stem cells maintain the chondrogenic phenotype of tissue-engineered cartilage. Stem Cell Res Ther 7:70. https://doi.org/10.1186/s13287-016-0328-x

41. Xing SC, Liu Y, Feng Y, Jiang C, Hu YQ, Sun W, Wang XH, Wei ZY, Qi M, Liu J, Zhai LJ, Wang ZQ (2015) Chondrogenic differentiation of ChM-I gene transfected rat bone marrow-derived mesenchymal stem cells on 3-dimensional poly (L-lactic acid) scaffold for cartilage engineering. Cell Biol Int 39:300-309. https://doi. org/10.1002/cbin.10393

42. Lin X, Wang L, Wang F (2017) ChondromodulinI suppresses tumorigenesis of human osteosarcoma cells. Mol Med Rep 16:8542-8548. https://doi.org/10.3892/mmr.2017.7629

43. von Heyking K, Calzada-Wack J, Gollner S, Neff F, Schmidt O, Hensel T, Schirmer D, Fasan A, Esposito I, Muller-Tidow C, Sorensen PH, Burdach S, Richter GHS (2017) The endochondral bone protein CHM1 sustains an undifferentiated, invasive phenotype, promoting lung metastasis in Ewing sarcoma. Mol Oncol 11:1288-1301. https://doi.org/10.1002/1878-0261.12057

44. Blaeschke F, Thiel U, Kirschner A, Thiede M, Rubio RA, Schirmer D, Kirchner T, Richter GHS, Mall S, Klar R, Riddell S, Busch DH, Krackhardt A, Grunewald TG, Burdach S (2016) Human HLA-A*02:01/CHM1+ allo-restricted T cell receptor transgenic CD8 $+\mathrm{T}$ cells specifically inhibit Ewing sarcoma growth in vitro and in vivo. Oncotarget 7:43267-43280. https:// doi.org/10.18632/oncotarget.9218

45. Thiel U, Schober SJ, Einspieler I, Kirschner A, Thiede M, Schirmer D, Gall K, Blaeschke F, Schmidt O, Jabar S, Ranft A, Alba Rubio R, Dirksen U, Grunewald TGP, Sorensen PH, Richter GHS, von Luttichau IT, Busch DH, Burdach SEG (2017) Ewing sarcoma partial regression without GvHD by chondromodulin-I/HLA-A*02:01-specific allorestricted $\mathrm{T}$ cell receptor transgenic T cells. Oncoimmunology 6:e1312239. https://doi. org/10.1080/2162402X.2017.1312239

46. Zhang P, Wang Y, Xu P, Song S, Zhu X, Shi Z, Gao S, Feng $\mathrm{X}$ (2015) Chondromodulin-1 functions as a tumor suppressor in gastric adenocarcinoma. Int J Oncol 47:941-950. https://doi. org/10.3892/ijo.2015.3081

47. Jain S, Watson MA, DeBenedetti MK, Hiraki Y, Moley JF, Milbrandt J (2004) Expression profiles provide insights into early malignant potential and skeletal abnormalities in multiple endocrine neoplasia type 2B syndrome tumors. Cancer Res 64:39073913. https://doi.org/10.1158/0008-5472.CAN-03-3801

48. Kusafuka K, Hiraki Y, Shukunami C, Yamaguchi A, Kayano T, Takemura T (2001) Cartilage-specific matrix protein chondromodulin-I is associated with chondroid formation in salivary pleomorphic adenomas: immunohistochemical analysis. Am J Pathol 158:1465-1472. https://doi.org/10.1016/S0002-9440(10)64097-7

49. Dou X, Li X, Yu H, Dong B (2018) Dual roles of ascidian chondromodulin-1: promoting cell proliferation whilst suppressing the growth of tumor cells. Mar Drugs 16:59. https://doi.org/10.3390/ md16020059

50. Mera H, Kawashima H, Yoshizawa T, Ishibashi O, Ali MM, Hayami T, Kitahara H, Yamagiwa H, Kondo N, Ogose A, Endo N, Kawashima H (2009) Chondromodulin-1 directly suppresses growth of human cancer cells. BMC Cancer 9:166. https://doi. org/10.1186/1471-2407-9-166

51. Patra D, Sandell LJ (2012) Antiangiogenic and anticancer molecules in cartilage. Expert Rev Mol Med 14:e10. https://doi. org/10.1017/erm.2012.3

52. Lin ML, Chen SS, Ng SH (2015) CHM-1 suppresses formation of cell surface-associated GRP78-p85alpha complexes, inhibiting PI3K-AKT signaling and inducing apoptosis of human nasopharyngeal carcinoma cells. Anticancer Res 35:5359-5368

53. Shao J, Gan L, Wang J (2016) Transfection of chondromodulin I into human breast cancer cells and its effect on the inhibition of cancer cell growth. Mol Med Rep 13:4303-4308. https://doi. org/10.3892/mmr.2016.5079

54. Grammer JB, Eichinger WB, Bleiziffer S, Benz MR, Lange R, Bauernschmitt R (2007) Valvular chondromodulin-1 expression is downregulated in a rabbit model of infective endocarditis. J Heart Valve Dis 16:623-630 (discussion 630)

55. Adkisson HD, Milliman C, Zhang X, Mauch K, Maziarz RT, Streeter PR (2010) Immune evasion by neocartilage-derived chondrocytes: Implications for biologic repair of joint articular cartilage. Stem Cell Res 4:57-68. https://doi.org/10.1016/j.scr.2009.09.004

56. Kusumoto D, Fukuda K (2013) The role of angiogenetic factors in the pathogenesis and the progression of cardiac valve disease. Clin Calcium 23:481-488 (doi: CliCa1304481488)

57. Hakuno D, Kimura N, Yoshioka M, Mukai M, Kimura T, Okada Y, Yozu R, Shukunami C, Hiraki Y, Kudo A, Ogawa S, Fukuda K (2010) Periostin advances atherosclerotic and rheumatic cardiac valve degeneration by inducing angiogenesis and MMP production in humans and rodents. J Clin Invest 120:2292-2306. https:// doi.org/10.1172/JCI40973

58. Sapp MC, Krishnamurthy VK, Puperi DS, Bhatnagar S, Fatora G, Mutyala N, Grande-Allen KJ (2016) Differential cell-matrix responses in hypoxia-stimulated aortic versus mitral valves. J R Soc Interface. https://doi.org/10.1098/rsif.2016.0449

59. Miura S, Shukunami C, Mitsui K, Kondo J, Hiraki Y (2011) Localization of chondromodulin-I at the feto-maternal interface and its inhibitory actions on trophoblast invasion in vitro. BMC Cell Biol 12:34. https://doi.org/10.1186/1471-2121-12-34

60. Xu J, Cai H, Meng Q, Li Y, Chen G, Fang W, Long X (2016) IL-1beta-regulating angiogenic factors expression in perforated temporomandibular disk cells via NF-kappaB pathway. J Oral Pathol Med 45:605-612. https://doi.org/10.1111/jop.12420

Publisher's Note Springer Nature remains neutral with regard to jurisdictional claims in published maps and institutional affiliations. 